\title{
Frequency of alterations in the $M E F V$ gene and clinical signs in familial Mediterranean fever in Central Anatolia, Turkey
}

\author{
G.G. Ceylan ${ }^{1}$, C. Ceylan ${ }^{2}$ and E. Ozturk ${ }^{1}$ \\ 'Department of Medical Genetics, \\ Ankara Ataturk Education and Training Hospital, Ankara, Turkey \\ ${ }^{2}$ Department of Urology, \\ Turkiye Yuksek Ihtisas Education and Training Hospital, Ankara, Turkey
}

Corresponding author: G.G. Ceylan

E-mail: nil_cey@yahoo.com

Genet. Mol. Res. 11 (2): 1185-1194 (2012)

Received September 15, 2011

Accepted February 24, 2012

Published May 7, 2012

DOI http://dx.doi.org/10.4238/2012.May.7.4

\begin{abstract}
Familial Mediterranean fever is a recessive autoinflammatory disease that is frequent in Armenians, Jews, Arabs, and Turks. The $M E F V$ gene is responsible for this disease. We looked for $M E F V$ gene variations (polymorphism and mutations) in a population that resides in Central Anatolia, Turkey. DNA was extracted from peripheral blood leukocytes of 802 familial Mediterranean fever patients. The DNA sequence data were examined for approximately 150 different mutations and polymorphisms, including single nucleotide polymorphisms in different exons of the $M E F V$ gene. The male:female ratio of these patients was 1.44:1. Mutations were detected in $48.1 \%$ of the patients; $7.5 \%$ were homozygous, $11.1 \%$ were compound heterozygous and $31.5 \%$ had only one identifiable mutant allele. No mutations were detected in $51.9 \%$ of the patients. The main clinical characteristics of the patients were: abdominal pain in $20.6 \%$, arthritis in $22.9 \%$
\end{abstract}


and amyloidosis in $4.6 \%$. Sixty-six percent of patients had a family history of familial Mediterranean fever; $19.4 \%$ of the patients were found to have parental consanguinity. We conclude that the genetics of familial Mediterranean fever is more complex than has previously been reported; heterozygous patients presenting a severe phenotype should be further analyzed for less common secondary MEFV mutations, using gene sequencing.

Key words: $M E F V$ gene; DNA sequencing; Genetics; Mutation; Familial Mediterranean fever

\section{INTRODUCTION}

Familial Mediterranean fever (FMF: OMIM \#249100) is an autosomal recessive disorder characterized by recurrent attacks of pleuritis, febrile peritonitis and synovitis. It affects mainly Turks, Arabs, Armenians, and non-Ashkenazi Jews (Medlej-Hashim et al, 2010). A familial Mediterranean fever $(M E F V)$ gene has been identified on the short arm of chromosome 16 and several mutations in this gene have been demonstrated in FMF patients (Consortium TFF, 1997; Consortium TIF, 1997). The MEFV gene consists of 10 exons and encodes a 781-amino acid protein called pyrin, which is expressed in polymorphonuclear cells, cytokine-activated monocytes, dendritic cells, and synovial fibroblasts (Centola et al., 2000; Diaz et al., 2004). Because of the restricted expression of pyrin in innate immune cells, the major role of pyrin appears to be the regulation of inflammation (Kastner, 2005). Mutations interfere with the pyrin domain, allowing an uninterrupted inflammatory cascade. To date more than 150 mutation gene alterations located in the $M E F V$ gene have been identified (Öztürk et al., 2008). Five founding mutations M694V, V726A, M680I, M694I (in exon 10), and E148Q (in exon 2) are the most common MEFV mutations (Sarrauste De Menthière C, 2003; Milhavet et al., 2008). Several reports have shown that the M964V mutation is associated with severe disease featuring early onset, high frequency of attacks, the need for the high doses of colchicine and high frequency of amyloidosis in untreated patients (Saatçi et al., 1997; Mattitt et al., 2006; Düşünsel et al., 2008; Paşa et al., 2008; Jarjour, 2010). The syndrome also features high levels of erythrocyte sedimentation rate, C-reactive protein and serum amyloid A, but case-specific consensus on phenotype and genotype in FMF patients has not been reached (Aldea et al., 2004). The carrier frequency of MEFV mutations is quite high in the 4 classically affected populations, ranging from 37 to $39 \%$ in Armenians and Iraqi Jews to $20 \%$ in Turks, North African and Ashkenazi Jews and Arabs (Pras and Kastner, 1997; Shinar et al., 2000; Schouten et al., 2002, van Gijn et al., 2008).

All molecular genetic methods for detecting mutations are based on differences in the DNA sequence. Logically, DNA sequencing would appear to be the best approach to determining the mutations. DNA sequencing was originally performed by using radioactive labels for the detection of the reaction products, an approach that is unsuitable for clinical use. Current DNA sequencing protocols use fluorescent nucleotides to label the DNA. The sequence is then read with an automated instrument. DNA sequencing generally begins with polymerase chain reaction (PCR) amplification of DNA regions 
of interest, followed by sequencing reactions with the PCR products. Instruments that perform automated analysis of DNA sequencing gels are based on real-time detection of fluorescence-labeled sequencing reaction products (Olive and Bean, 1999). In this study, we examined the entire MEFV coding sequence of symptomatic FMF patients to look for mutations potentially missed by currently used screening methods. This study is the first to perform DNA sequence analysis on the whole MEFV coding sequence in all subjects.

\section{PATIENTS AND METHODS}

\section{Patients}

A total of 802 patients came to our laboratory because of FMF symptoms - especially abdominal, renal and arthralgia symptoms - between June 2008 and December 2010. They were referred from various clinics with specialties in rheumatology, urology, nephrology, and gastroenterology, among others. The mean age of the patients was 30.7 years. Written consent was obtained from all participants, and the review board at our institution approved the study.

\section{Diagnostic techniques}

We drew $5 \mathrm{~mL}$ blood from each patient into tubes containing ethylenediaminetetraacetic acid. DNA was extracted using a commercial kit (QIAamp DNA mini kit; Qiagen, Hilden, Germany). Sequencing was performed using a 48-well capillary machine (MegaBACE, Amersham) for the analysis of the whole MEFV coding sequence. All $M E F V$ gene exons were screened for causative mutations via direct DNA sequencing so as not to miss any mutations. We have applied this technique to approximately 150 different mutations and polymorphisms including single-nucleotide polymorphisms in different exons of the $M E F V$ gene. The sequencing data were analyzed using Sequencher 4.6 (Gene Codes, Ann Arbor, MI, USA). All nucleotide alterations were distinguished using this method.

\section{RESULTS}

The study included 802 patients with a male:female ratio of 1.44:1 (473 females, 329 males; mean age, $25.0 \pm 11.25$ years; range, 5-70 years). Mutations were detected in 386 (48.1\%) patients; 53 (7.5\%) were homozygous, 87 (11.1\%) were compound heterozygous, and $246(31.5 \%)$ had only one identifiable mutant allele. No mutations were detected in $416(51.9 \%)$ patients (Table 1$)$. The age of the male patients ranged from 5 to 75 years. The mean age was 31 years. The age of the female patients ranged from 3 to 72 years. The mean age was 29 years. The mean ages of the patients with and without FMF mutations regardless of gender were 30 and 31 years, respectively. The mean age of patients with $M E F V$ gene mutations was 30 years.

The main clinical characteristics of the patients were as follows: abdominal pain in $20.6 \%$, arthritis in $22.9 \%$, and amyloidosis in $4.6 \%$. Sixty-six percent of patients had a positive family history of FMF. The presence of parental consanguinity was also deter- 
mined for all patients, and it occurred in $19.4 \%$ of patients. MEFV mutations were studied using a whole $M E F V$ gene sequencing method. No mutations were detected in 416 patients (51.9\%; Table 2). Results in $802 \mathrm{FMF}$ patients revealed that M694V was the most frequent mutation (28\%), followed by V726A (11.7\%), E148Q (9.1\%), and M680I(G/C) $(3.9 \%)$ in the Central Anatolian population (Figure 1). The rarest mutations were heterozygous forms of F479L (in exon 5), M694I (in exon 10), E225D, E230K, T267I (all three in exon 2), I591T (in exon 9), and combined heterozygous forms of E148Q/V726A, E148Q/M694I, E167D/M694V, E167D/F479L (E167D is in exon 2), M694V/K695R, M694V/F479L, M694V/M694I, M694I/V726A, and M694V/P369S. The frequency of the rare mutations was $0.03 \%$ (only one patient had all of these mutations). Most of the rare mutations were heterozygous. Four common mutations (M694V, E148Q, M680I(G/C), and V726A) were found in $52.7 \%$ of patients (Figure 2). The study population had a high rate of carriers.

Table 1. Clinical symptoms and results of mutation analysis of the patients with different $M E F V$ gene mutations.

\begin{tabular}{|c|c|c|c|c|}
\hline \multicolumn{2}{|c|}{ Mutation } & \multicolumn{3}{|c|}{ Number of patients with different FMF symptoms (N) } \\
\hline Allele 1 & Allele 2 & Abdominal pain & Arthritis & Amyloidosis \\
\hline M694V & V726A & 8 & 8 & 6 \\
\hline M694V & M694V & 13 & 13 & 7 \\
\hline V726A & V726A & 2 & - & - \\
\hline E148Q & E148Q & 4 & 1 & - \\
\hline A744S & - & 7 & 8 & - \\
\hline V726A & - & 23 & 15 & 7 \\
\hline M694V & - & 49 & 54 & 6 \\
\hline M680I(G/C) & - & 8 & 6 & 1 \\
\hline M680I(G/C) & M680I(G/C) & 3 & 5 & 1 \\
\hline P369S & - & 5 & 3 & - \\
\hline E148Q & - & 11 & 22 & 2 \\
\hline E148Q & M694V & 3 & 9 & 1 \\
\hline M680I(G/C) & M694V & 5 & 5 & 1 \\
\hline K695R & - & 5 & 3 & - \\
\hline M680I(G/C) & V726A & 6 & 3 & 3 \\
\hline M694V & $\mathrm{R} 761 \mathrm{H}$ & 3 & - & - \\
\hline E148Q & P369S & 1 & 7 & - \\
\hline T267I & - & 1 & - & - \\
\hline M694V & F479L & 1 & - & - \\
\hline E225D & - & 1 & - & - \\
\hline $\mathrm{I} 259 \mathrm{~V}$ & - & 1 & - & - \\
\hline V726A & $\mathrm{R} 761 \mathrm{H}$ & 1 & 1 & - \\
\hline M694I & - & 1 & - & - \\
\hline $\mathrm{R} 761 \mathrm{H}$ & - & 1 & 4 & - \\
\hline A744S & A744S & 1 & 3 & - \\
\hline F479L & - & 1 & - & - \\
\hline P369S & M694V & - & 1 & - \\
\hline E167D & M694V & - & 1 & - \\
\hline M694V & K695R & - & 1 & - \\
\hline M680I(G/C) & $\mathrm{R} 761 \mathrm{H}$ & - & 3 & - \\
\hline E148Q & M694I & - & 1 & - \\
\hline E148Q & V726A & - & 1 & - \\
\hline E148Q & M680I(G/C) & - & 1 & 2 \\
\hline I591T & - & - & 1 & - \\
\hline E230K & - & - & 1 & - \\
\hline E167D & F479L & - & 2 & - \\
\hline M694I & M694V & - & 1 & - \\
\hline Total & & 165 & 184 & 37 \\
\hline
\end{tabular}


Table 2. Genotypes and frequency of detected mutations in Turkish population.

\begin{tabular}{|c|c|c|c|}
\hline \multirow[t]{2}{*}{ Mutation type } & \multirow[t]{2}{*}{ Genotype } & \multicolumn{2}{|c|}{ Patients } \\
\hline & & $\mathrm{N}$ & $\%$ \\
\hline \multirow[t]{16}{*}{ Heterozygous } & M694V & 108 & 28.0 \\
\hline & E148Q & 35 & 9.1 \\
\hline & M680I(G/C) & 15 & 3.9 \\
\hline & V726A & 45 & 11.7 \\
\hline & A744S & 15 & 3.9 \\
\hline & P369S & 8 & 2.1 \\
\hline & $\mathrm{R} 761 \mathrm{H}$ & 5 & 1.3 \\
\hline & F479L & 1 & 0.3 \\
\hline & M694I & 1 & 0.3 \\
\hline & K695R & 8 & 2.1 \\
\hline & E225D & 1 & 0.3 \\
\hline & E230K & 1 & 0.3 \\
\hline & $\mathrm{I} 259 \mathrm{~V}$ & 1 & 0.3 \\
\hline & I591T & 1 & 0.3 \\
\hline & T267I & 1 & 0.3 \\
\hline & Total & 246 & 63.8 \\
\hline \multirow[t]{19}{*}{ Compound heterozygous } & E148Q/M680I(G/C) & 3 & 0.8 \\
\hline & E148Q/V726A & 1 & 0.3 \\
\hline & E148Q/M694V & 13 & 3.4 \\
\hline & E148Q/P369S & 8 & 2.1 \\
\hline & E148Q/M694I & 1 & 0.3 \\
\hline & E167D/M694V & 1 & 0.3 \\
\hline & E167D/F479L & 2 & 0.5 \\
\hline & $\mathrm{M} 680 \mathrm{I}(\mathrm{G} / \mathrm{C}) / \mathrm{V} 726 \mathrm{~A}$ & 12 & 3.1 \\
\hline & $\mathrm{M} 680 \mathrm{I}(\mathrm{G} / \mathrm{C}) / \mathrm{R} 761 \mathrm{H}$ & 3 & 0.8 \\
\hline & M680I(G/C)/M694V & 11 & 2.8 \\
\hline & M694V/R761H & 3 & 0.8 \\
\hline & M694V/K695R & 1 & 0.3 \\
\hline & M694V/F479L & 1 & 0.3 \\
\hline & M694V/M694I & 1 & 0.3 \\
\hline & M694I/V726A & 1 & 0.3 \\
\hline & M694V/P369S & 1 & 0.3 \\
\hline & M694V/V726A & 22 & 5.7 \\
\hline & $\mathrm{V} 726 \mathrm{~A} / \mathrm{R} 761 \mathrm{H}$ & 2 & 0.5 \\
\hline & Total & 87 & 22.5 \\
\hline \multirow[t]{9}{*}{ Homozygous } & A744S & 4 & 1.0 \\
\hline & E148Q & 5 & 1.3 \\
\hline & M680I(G/C) & 9 & 2.3 \\
\hline & M694V & 33 & 8.5 \\
\hline & V726A & 2 & 0.5 \\
\hline & Total & 53 & 13.7 \\
\hline & Patients with MEFV mutations & 386 & 48.1 \\
\hline & Patients without MEFV mutations & 416 & 51.9 \\
\hline & Total & 802 & 100.0 \\
\hline
\end{tabular}

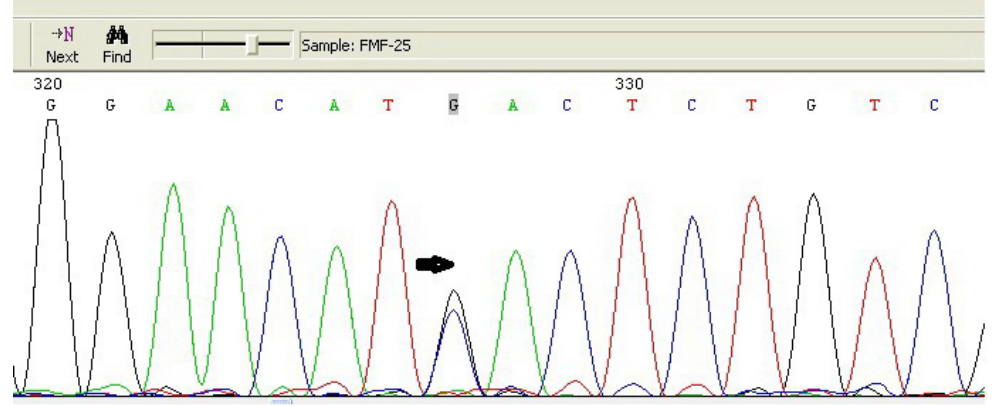

Figure 1. Chromatogram of a patient with M680I(G/C) heterozygosity (arrow). 

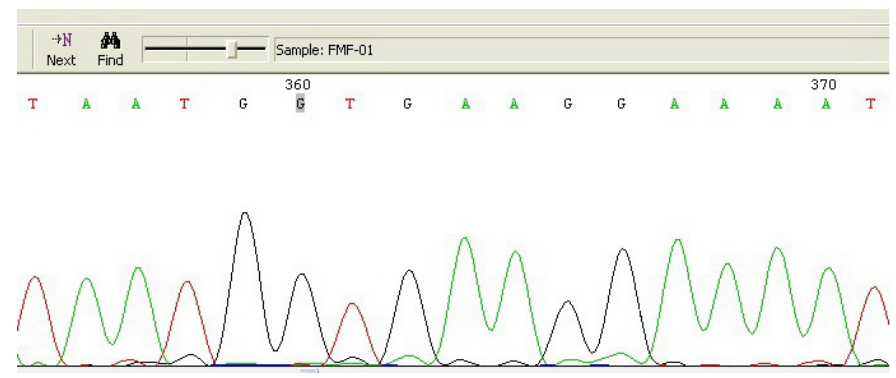

Figure 2. Chromatogram of a patient with M694V homozygosity.

In addition to 7 synonymous polymorphisms in exon 2 (D102D, G138G, and A165A), exon 3 (R314R), and exon 5 (E474E, Q476Q, and D510D), we found a T267I mutation in one heterozygous patient, E225D in one heterozygous patient, E230K in one heterozygous patient, I259V in one heterozygous patient, I591T in one heterozygous patient, F479L in one heterozygous patient, and M694I in one heterozygous patient. These additional mutations were found in different patients and these patients were severe cases of FMF (Table 3). These mutations are nucleotide variations located in exons 2, 5, 9, and 10 that are not explored with denaturing gradient gel electrophoresis or reverse dot methods.

\section{DISCUSSION}

The identification of the $M E F V$ gene and its various mutations provides a rational basis for medical and genetic counseling for the clinical treatment of FMF patients and their families. The prevalence of this disease in Turkey is approximately $0.1 \%$, but it is estimated that the prevalence may be higher because many patients remain undiagnosed, particularly if they have mild forms of the disease. Furthermore, in Turkey, especially central Anatolia, in which consanguinity is widespread, the incidence of FMF may be higher than that observed. Ankara is situated in the center of Anatolia and receives migration from Central Anatolia, East Anatolia, and the Black Sea region. It is also a referral center for patients from those regions, and our laboratory is one of the main referral institutions. Therefore, the results of our study are representative of the populations living in those regions of Turkey. Most studies of FMF have reported that the disease affects both genders in a similar ratio (Saatçi et al., 1997; Milhavet et al., 2008). MEFV gene mutations were similar in male and female FMF patients in our study. Likewise, clinical characteristics were generally comparable between males and females, although some features, such as abdominal pain or arthritis, occasionally differ.

$M E F V$ gene mutations vary according to population characteristics such as familial history, parental consanguinity, migration, population type, and the presence of heterozygous carriers. Both the types and the frequency of mutation in such populations should be examined to protect the health of future generations (Marek-Yagel et al., 2009).

In addition to clinical criteria, molecular studies for detecting disease-causing mutations are needed to confirm the diagnosis of FMF. Sequence analysis is quite precious in FMF diagnoses. We suggest this reliable and safe method for diagnosis in large FMF patient groups. The analysis of the whole $M E F V$ gene has shown that $\mathrm{M} 694 \mathrm{~V}$ is the most frequent mutation in the population from Central Anatolia. Analysis of all mutations in the $M E F V$ gene confirmed 
Characterization of familial Mediterranean fever in Turkey

Table 3. MEFV genotypes and allele frequencies among 802 FMF Turkish patients.

\begin{tabular}{|c|c|c|}
\hline \multicolumn{3}{|l|}{ A. Genotypes } \\
\hline \multicolumn{2}{|c|}{ Genotype } & \multirow[t]{2}{*}{ Number of patients } \\
\hline Allele 1 & Allele 2 & \\
\hline E148Q & P369S & 8 \\
\hline E148Q & $\mathrm{M} 680 \mathrm{I}(\mathrm{G} / \mathrm{C})$ & 3 \\
\hline E148Q & M694V & 13 \\
\hline E148Q & M694I & 1 \\
\hline E148Q & V726A & 1 \\
\hline E167D & F479L & 2 \\
\hline E167D & M694V & 1 \\
\hline M680I(G/C) & M694V & 11 \\
\hline $\operatorname{M680I}(G / C)$ & $\mathrm{R} 761 \mathrm{H}$ & 3 \\
\hline $\mathrm{M} 680 \mathrm{I}(\mathrm{G} / \mathrm{C})$ & V726A & 12 \\
\hline M694V & F479L & 1 \\
\hline M694V & K695R & 1 \\
\hline M694V & M694I & 1 \\
\hline M694V & P369S & 1 \\
\hline M694V & $\mathrm{R} 761 \mathrm{H}$ & 3 \\
\hline M694V & V726A & 22 \\
\hline M694I & V726A & 1 \\
\hline V726A & $\mathrm{R} 761 \mathrm{H}$ & 2 \\
\hline M694V & wt & 108 \\
\hline E148Q & wt & 35 \\
\hline $\operatorname{M680I}(G / C)$ & wt & 15 \\
\hline V726A & wt & 45 \\
\hline A744S & wt & 15 \\
\hline P369S & wt & 8 \\
\hline $\mathrm{R} 761 \mathrm{H}$ & wt & 5 \\
\hline F479L & wt & 1 \\
\hline M694I & wt & 1 \\
\hline K695R & wt & 8 \\
\hline E225D & wt & 1 \\
\hline $\mathrm{E} 230 \mathrm{~K}$ & wt & 1 \\
\hline $\mathrm{I} 259 \mathrm{~V}$ & wt & 1 \\
\hline I591T & wt & 1 \\
\hline T267I & wt & 1 \\
\hline A744S & A744S & 4 \\
\hline E148Q & E148Q & 5 \\
\hline $\operatorname{M680I}(\mathrm{G} / \mathrm{C})$ & $\operatorname{M680I}(\mathrm{G} / \mathrm{C})$ & 9 \\
\hline M694V & M694V & 33 \\
\hline V726A & V726A & 2 \\
\hline wt & wt & 416 \\
\hline Total & & 802 \\
\hline \multicolumn{3}{|c|}{ B. Allele frequencies } \\
\hline Mutation & No. of alleles & Frequency \\
\hline$\overline{\text { E148Q }}$ & 71 & 0.044 \\
\hline E167D & 3 & 0.002 \\
\hline $\mathrm{M} 680 \mathrm{I}(\mathrm{G} / \mathrm{C})$ & 62 & 0.040 \\
\hline M694V & 228 & 0.142 \\
\hline M694I & 3 & 0.002 \\
\hline V726A & 87 & 0.054 \\
\hline $\mathrm{R} 761 \mathrm{H}$ & 13 & 0.008 \\
\hline A744S & 23 & 0.014 \\
\hline K695R & 9 & 0.006 \\
\hline F479L & 4 & 0.003 \\
\hline P369S & 17 & 0.010 \\
\hline $\mathrm{E} 225 \mathrm{D}$ & 1 & 0.0006 \\
\hline $\mathrm{E} 230 \mathrm{~K}$ & 1 & 0.0006 \\
\hline $\mathrm{I} 259 \mathrm{~V}$ & 1 & 0.0006 \\
\hline I591T & 1 & 0.0006 \\
\hline T267I & 1 & 0.0006 \\
\hline Total mutant & 525 & 0.327 \\
\hline Wild type (wt) & 1079 & 0.673 \\
\hline Total & 1604 & 1.000 \\
\hline
\end{tabular}


the diagnosis of FMF in $48.1 \%$ of these patients. The most common mutations were M694V, V726A, E148Q, and M680I(G/C). M694V was the most frequent mutation in patients with abdominal pain and arthritis in our study. Interestingly, M694V homozygosity and V726A heterozygosity were found more frequently in amyloidosis patients. The allele frequency of the M694V mutation was 0.0142 , and a total of 195 (24.3\%) patients had this mutation. M694V homozygotes accounted for $4.1 \%$ of the patients, $13.5 \%$ were M694V heterozygotes, and $17.6 \%$ were M694V compound heterozygotes. In previous studies, M694V was detected in 69-80\% of FMF patients with arthritis and abdominal pain (Ince et al., 2002; Olgun et al., 2005). The M694V mutation is the most prevalent mutation in Arabs (Mattit et al., 2006; Jarjour, 2010), Lebanese, and Jordanians (Medlej-Hashim et al., 2000, 2005), Turks (Yalçınkaya et al., 2000; Güneşaçar et al., 2005), Armenians (Cazeneuve et al., 1999), Iranian Azeri Turks (Esmaeili et al., 2008), and Jews (Dewalle, 1998; Touitou, 2001).

An association between homozygosity for the M694V mutation and arthritis in FMF patients has been reported by others (Brik et al., 1999; Kone et al., 2000; Olgun et al., 2005). The clinical presentation of arthritis in FMF has variable forms. The M694V mutation is most likely associated with arthritis, one of the severe complications of FMF. All arthritis patients in Central Anatolia should be evaluated for FMF to prevent the development of chronic arthritis, abdominal pain, and amyloidosis. Data on genotype-phenotype correlation in FMF generally agree with the presence of M694V homozygosity and its correlation with the most severe FMF phenotypes and amyloidosis (Dewalle et al., 1998; Cazeneuve et al., 1999; Kone et al., 2000; Olgun et al., 2005; Jarjour, 2010; Jarjour and Dodaki, 2011).

The most serious complication in FMF patients is chronic renal failure, which is highly associated with point mutations in the $M E F V$ gene. The population in our study had a high rate of carriers, and V726A had the second-highest mutation frequency when our results were compared with those of other regions of Turkey and other Mediterranean groups (Shinar et al., 2000). Therefore, we expect that the M694V mutation, which causes the worst pathologic phenotype, must be the mutation with the least penetration in patients with FMF (Marek-Yagel et al., 2009; Jarjour and Dodaki, 2011). According to our study, chronic renal failure patients in the Central Anatolian population have a high rate of MEFV homozygous (M694V) and heterozygous (V726A) gene mutations.

In conclusion, $M E F V$ gene mutations vary according to population characteristics such as familial history, parental consanguinity, migration, the presence of heterozygous carriers, and intrapopulation differentiation. Populations similar to the one in our study should be examined for mutation types and frequency to protect the health of future generations. Our study shows that the genetics of FMF are more complex than previously been appreciated and supports the mounting evidence that a single MEFV mutation may be associated with mild FMF symptoms. However, heterozygous patients presenting severe phenotypes should be further analyzed for less common second MEFV mutations using gene sequencing. In addition, our results have important implications for genetic counseling. We believe that this study will be helpful to clinicians by indicating the most frequently encountered FMF mutations in the Turkish population. Despite the current body of knowledge about FMF, prospective clinical studies with large numbers of patients across various ethnic groups will help to clarify this considerably debilitating disease.

The authors state that they have no conflict of interest. 


\section{REFERENCES}

Aldea A, Campistol JM, Arostegui JI, Rius J, et al. (2004). A severe autosomal-dominant periodic inflammatory disorder with renal AA amyloidosis and colchicine resistance associated to the MEFV H478Y variant in a Spanish kindred: an unusual familial Mediterranean fever phenotype or another MEFV-associated periodic inflammatory disorder? Am. J. Med. Genet. A 124A: 67-73.

Brik R, Shinawi M, Kepten I, Berant M, et al. (1999). Familial Mediterranean fever: clinical and genetic characterization in a mixed pediatric population of Jewish and Arab patients. Pediatrics 103: e70.

Cazeneuve C, Sarkisian T, Pecheux C, Dervichian M, et al. (1999). MEFV-Gene analysis in armenian patients with Familial Mediterranean fever: diagnostic value and unfavorable renal prognosis of the M694V homozygous genotype-genetic and therapeutic implications. Am. J. Hum. Genet. 65: 88-97.

Centola M, Wood G, Frucht DM, Galon J, et al. (2000). The gene for familial Mediterranean fever, MEFV, is expressed in early leukocyte development and is regulated in response to inflammatory mediators. Blood 95: 3223-3231.

Consortium TFF (1997). A candidate gene for familial Mediterranean fever. Nat. Genet. 17: 25-31.

Consortium TIF (1997). Ancient missense mutations in a new member of the RoRet gene family are likely to cause familial Mediterranean fever. The International FMF Consortium. Cell 90: 797-807.

Dewalle M, Domingo C, Rozenbaum M, Ben-Chetrit E, et al. (1998). Phenotype-genotype correlation in Jewish patients suffering from familial Mediterranean fever (FMF). Eur. J. Hum. Genet. 6: 95-97.

Diaz A, Hu C, Kastner DL, Schaner P, et al. (2004). Lipopolysaccharide-induced expression of multiple alternatively spliced MEFV transcripts in human synovial fibroblasts: a prominent splice isoform lacks the C-terminal domain that is highly mutated in familial Mediterranean fever. Arthritis Rheum. 50: 3679-3689.

Düşünsel R, Dursun I, Gunduz Z, Poyrazoglu MH, et al. (2008). Genotype-phenotype correlation in children with familial Mediterranean fever in a Turkish population. Pediatr. Int. 50: 208-212.

Esmaeili M, Bonyadi M, Rafeey M, Sakha K, et al. (2008). Common MEFV mutation analysis in Iranian Azeri Turkish patients with familial Mediterranean fever. Semin. Arthritis Rheum. 37: 334-338.

Güneşaçar R, Kasap H, Erken E and Ozer HT (2005). Comparison of amplification refractory mutation system and polymerase chain reaction-restriction fragment length polymorphism techniques used for the investigation of MEFV gene exon 10 point mutations in familial Mediterranean fever patients living in Cukurova region (Turkey). Genet. Test 9: 220-225.

Ince E, Cakar N, Tekin M, Kendirli T, et al. (2002). Arthritis in children with familial Mediterranean fever. Rheumatol. Int. 21: 213-217.

Sarrauste De Menthière C, Terrière S, Pugnère D, Ruiz M, et al. (2003). INFEVERS: The Registry for FMF and Hereditary İnflammatory Disorders Mutations. Nucleic Acids Res. 31: 282-285.

Jarjour RA (2010). Familial Mediterranean fever in Syrian patients: MEFV gene mutations and genotype-phenotype correlation. Mol. Biol. Rep. 37: 1-5.

Jarjour RA and Dodaki R (2011). Arthritis patterns in familial Mediterranean fever patients and association with M694V mutation. Mol. Biol. Rep. 38: 2033-2036.

Kastner DLAI (2005). Lippincott Williams and Wilkins. Vol. 15. Intermittent and Periodic Arthritis Syndromes, Philadelphia.

Kone PI, Dubuc M, Sportouch J, Minodier P, et al. (2000). Phenotype-genotype correlation in 91 patients with familial Mediterranean fever reveals a high frequency of cutaneomucous features. Rheumatology 39: 1275-1279.

Marek-Yagel D, Berkun Y, Padeh S, Abu A, et al. (2009). Clinical disease among patients heterozygous for familial Mediterranean fever. Arthritis Rheum. 60: 1862-1866.

Mattit H, Joma M, Al-Cheikh S, El-Khateeb M, et al. (2006). Familial Mediterranean fever in the Syrian population: gene mutation frequencies, carrier rates and phenotype-genotype correlation. Eur. J. Med. Genet. 49: 481-486.

Medlej-Hashim M, Rawashdeh M, Chouery E, Mansour I, et al. (2000). Genetic screening of fourteen mutations in Jordanian familial Mediterranean fever patients. Hum. Mutat. 15: 384.

Medlej-Hashim M, Serre JL, Corbani S, Saab O, et al. (2005). Familial Mediterranean fever (FMF) in Lebanon and Jordan: a population genetics study and report of three novel mutations. Eur. J. Med. Genet. 48: 412-420.

Medlej-Hashim M, Nehme N, Chouery E, Jalkh N, et al. (2010). 1Novel MEFV transcripts in Familial Mediterranean fever patients and controls. BMC Med. Genet. 11: 87.

Milhavet F, Cuisset L and Hoffman HM (2008). The infevers autoinflammatory mutation online registry: update with new genes and functions. Hum. Mutat. 29: 803-808.

Olgun A, Akman S, Kurt I, Tuzun A, et al. (2005). MEFV mutations in familial Mediterranean fever: association of M694V homozygosity with arthritis. Rheumatol. Int. 25: 255-259.

Olive DM and Bean P (1999). Principles and applications of methods for DNA-based typing of microbial organisms. $J$. 
Clin. Microbiol. 37: 1661-1669.

Öztürk A, Özçakar B, Ekim M and Akar N (2008). Is MEFV gene Arg202Gln (605 G>A) a disease-causing mutation? Turk. J. Med. Sci. 38: 205-208.

Paşa S, Altintas A, Devecioglu B, Cil T, et al. (2008). Familial Mediterranean fever gene mutations in the Southeastern region of Turkey and their phenotypical features. Amyloid 15: 49-53.

Pras M and Kastner DL (1997). Familial Mediterranean Fever. In: Rheumatology. 2nd edn. (Klippel JH and Dieppe PA, eds.). Mosby, London, 1-23.

Saatçi U, Ozen S, Ozdemir S, Bakkaloglu A, et al. (1997). Familial Mediterranean fever in children: report of a large series and discussion of the risk and prognostic factors of amyloidosis. Eur. J. Pediatr. 156: 619-623.

Schouten JP, McElgunn CJ, Waaijer R, Zwijnenburg D, et al. (2002). Relative quantification of 40 nucleic acid sequences by multiplex ligation-dependent probe amplification. Nucleic Acids Res. 30: e57.

Shinar Y, Livneh A, Langevitz P, Zaks N, et al. (2000). Genotype-phenotype assessment of common genotypes among patients with familial Mediterranean fever. J. Rheumatol. 27: 1703-1707.

Touitou I (2001). The spectrum of Familial Mediterranean Fever (FMF) mutations. Eur. J. Hum. Genet. 9: 473-483.

van Gijn ME, Soler S, de la Chapelle C, Mulder M, et al. (2008). Search for copy number alterations in the MEFV gene using multiplex ligation probe amplification, experience from three diagnostic centres. Eur. J. Hum. Genet. 16: 1404-1406.

Yalçınkaya F, Cakar N, Misirlioglu M, Tumer N, et al. (2000). Genotype-phenotype correlation in a large group of Turkish patients with familial mediterranean fever: evidence for mutation-independent amyloidosis. Rheumatology 39: 67-72. 